Research Journal of Animal Sciences 6 (1): 12-25, 2012

ISSN: $1993-5269$

(C) Medwell Journals, 2012

\title{
Prevalence of Pathogenic Leptospires in Rats from Selected Locations in Peninsular Malaysia
}

\author{
S.N. Mohamed-Hassan, A.R. Bahaman, A.R. Mutalib and S. Khairani-Bejo \\ Faculty of Veterinary Medicine, Universiti Putra Malaysia, 43400 Serdang, Selangor, Malaysia
}

\begin{abstract}
Rats are considered as one of the most important sources of leptospirosis as they are present in abundance in many environments. They caused significant economic losses and served as reservoirs for many zoonotic diseases. One of the diseases is leptospirosis which is considered a re-emerging disease in Malaysia. However, knowledge of the epizootic of leptospirosis and leptospiral serovars associated with rats is lacking. The objectives of the study therefore were to determine the distribution of rat's species and their carrier status. In Malaysia, R. tiomanicus was found to be the dominant species found in Malaysian environments and it constitutes $86.0 \%$ ( 420 out of 488 rats) of the rats caught in different types of localities; National Service Training Camps (Kelantan, Terengganu, Malacca and Selangor), oil palm estates (Terengganu and Malacca), Royal Belum Rainforest (Perak), Suburban areas (Kelantan and Perak) and PULAPOL (Negeri Sembilan). Sixty leptospiral isolates $(12.3 \%)$ were successfully cultured from the kidneys of the rats caught. Polymerase Chain Reaction (PCR) assay revealed $42(8.6 \%)$ of the isolates were pathogenic as disclosed by the $16 \mathrm{~S}$ primers. Majority of the pathogenic leptospires were isolated from rats caught in the National Service Training Camps (NSTC). The high rate in NSTC posed a major threat to the trainees as they were frequently involved in outdoor activities and exposed to infected environment. Therefore, control of rat population is crucial in minimizing the risk of transmitting leptospirosis to human.
\end{abstract}

Key words: Pathogenic leptospires, rats, culture, PCR, epizootic, Malaysia

\section{INTRODUCTION}

According to Hinds et al. (2003), almost four millions of rats are born every day in developing nations. The increase in rat population poses a health risk to humans and domestic animals as they tend to live in proximity with them. Rats present in abundance in nature and they make up to $42 \%$ of the known mammalian species.

Their role as pest in the developed and developing countries caused significant losses primarily in agricultural and urban environments. Rodents from the Muridae family have been extensively studied because of their role as reservoirs for many zoonotic diseases. One of the diseases is leptospirosis which is considered as an emerging disease in some countries. In Malaysia, leptospirosis is a re-emerging disease as a number of outbreaks were reported recently however, little is known about the epizootic of leptospirosis and leptospiral serovars associated with them.

Rats are considered as one of the most important sources of leptospirosis (Faine et al., 1999). They have long been reported as carrier for pathogenic Leptospira and it was first isolated from wild rats by Noguchi (1917) causing death after inoculation in guinea pigs. Since, the first isolation, many studies have been conducted to investigate the role of rats in human leptospirosis (Matthias et al., 2008; Vinetz et al., 1996). Rats are resistant to leptospiral infection (Nally et al., 2005) and carrier for many pathogenic leptospiral serovars. Pathogenic leptospires have been successfully isolated from the kidneys of various species of rats (Gordon-Smith et al., 1961; Vedhagiri and Natarajaseenivasan, 2010).

According to Gordon-Smith et al. (1961), most of the leptospires isolated were from rats $(32 \%)$ while a few isolates were obtained from other small mammals. Recently in Malaysia, R. tiomanicus was found to be dominant species and carrier for serovar icterohaemorrhagiae, canicola, ballum, pyrogenes and hebdomadis (Mohamed-Hassan et al., 2010). In a study conducted in India showed that $R$. norvegicus was found positive with serovar autumnalis, javanica, icterohaemorrhagiae and pomona (Vedhagiri and Natarajaseenivasan, 2010) however, serovar copenhageni was found dominant in the same species of rats caught in Brazil (Faria et al., 2008).

Corresponding Author: S.N. Mohamed-Hassan, Faculty of Veterinary Medicine, Universiti Putra Malaysia, 43400 Serdang, Selangor, Malaysia 
Leptospirosis has a wide variety of clinical symptoms and it becomes the main reason for the difficulties in diagnosis. The symptoms are easily mistaken with many other diseases. Laboratory analysis for leptospirosis is depending on the samples available and stage of the illness. There are many techniques available for the detection of leptospires either serology, bacteriology or by molecular methods. Direct examination of leptospires in urine and blood samples can be assisted with darkfield microscopy. The technique is considered cheap, economic and rapid however, there is some limitation as the concentration of leptospires presence may be too low and insensitive (Sharma and Kalawat, 2008) and the presence of artefacts from cellular elements can be easily mistaken for leptospires by an untrained person. Apart from direct examination, leptospires also can be isolated from clinical samples depending on the stage of infection. Leptospires can be isolated from blood (Wuthiekanun et al., 2007) CSF (Gangadhar et al., 2008) and dialysate fluid (Ahmad et al., 2005) during leptospiremia stage which usually occurs during the 1st week of illness (Wuthiekanun et al., 2007).

There are many techniques available for a quick detection of Leptospira such as immunofluorescence (Appassakij et al., 1995), immunoperoxidase staining (Silva et al., 2005) and DNA hybridization with oligonucleotide probes (Perolat et al., 1998; Brenner et al., 1999). In spite of their usefulness, these techniques require the microorganism to be present in relatively large numbers. Now a days, rapid detection of small numbers of leptospires in clinical samples can be performed by polymerase chain reaction assay (Merien et al., 1992). Polymerase Chain Reaction (PCR) assay is a technique which manipulates a pair of oligonucleotide primers that can amplify particular segments of DNA and produces many copies of it. Many primers were designed to target only pathogenic group of leptospires. Such primers include $\mathrm{G} 1 / \mathrm{G} 2$ and B64-I/B64II which were derived from genomic DNA libraries of Leptospira serovar icterohaemorrhagiae (strain RGA) and bim (strain 1051) enabled the detection of pathogenic leptospires (Gravekamp et al., 1993).

A pair of primers derived from the 16S rRNA gene of serovar canicola enabled direct detection of leptospires without first differentiating between pathogenic and saprophytic species (Merien et al., 1992). Many attempts have been performed to develop a method that will increase the sensitivity and specificity of primers for better detection of leptospiral DNA in clinical samples. Kee et al. (1994) reported that as little as $100 \mathrm{fg}$ of leptospiral DNA could be detected by LP1 and LP2 primers. Moreover, the primers could detect leptospiral DNA in blood samples of gerbils collected 2 days post infection.
Leptospirosis often occurs in tropical regions as the regions provided conditions favorable for the survival of leptospires outside their hosts. Risk of contracting leptospires is higher for people living in proximity with carrier animals especially rats. In Malaysia, the concern about leptospirosis has increased due to several outbreaks reported recently which were related with exposure to urine-contaminated water. Potential of rats as the main contributor for the human leptospiral cases in Malaysia should be investigated since the country has many species of rats. A study on the diversity of rats in four habitats (forest, urban, rice-field and coastal habitat) in the states of Selangor and Negeri Sembilan has been conducted recently. The outcomes of the study showed that three of the habitats (urban, coastal and rice-field) were dominated with Rattus rattus diardi. However, various species of rats were found to dominate the forest habitats (Paramasvaran et al., 2009). Rats are natural carrier for leptospires, their presence increase chances of getting infection from the environment. Different species of rats can be found in different geographical backgrounds and they are carrier for many serovars of pathogenic Leptospira.

Six states in Peninsular Malaysia were selected for their unique ecological settings and different human activities. These six states cover National Service Training Centre (NSTC), PULAPOL, oil palm estates and forest habitat. The National Service Training Centre or locally known as PLKN training camps are normally situated in rural areas.

Human cases in NSTC related with urinecontaminated water have drawn public attention about the safety of the trainees as they might be exposed to the urine-contaminated water through outdoor activities in the training camps. Leptospirosis is also known as occupational-related disease. Two oil palm estates situated in Terengganu and Malacca were selected in this study as various species of rats can be found such as Rattus tiomanicus (Miller), Rattus argentiventer and Rattus rattus diardi (Puan et al., 2011). Apart from causing damage to the plantation through their destructive behavior, the presence of rats poses a health risk to workers. The Royal Belum Rainforest was chosen because it has been subjected to various human activities; military training, hunting, ecotourism and home to the aboriginal people.

\section{MATERIALS AND METHODS}

Study sites: The study was conducted in six states of Peninsular Malaysia; Kelantan, Terengganu, Malacca, Perak, Negeri Sembilan and Selangor at ten different types 
of localities; 4 National Service Training Camps (NSTC), 2 oil palm estates, 2 suburban areas, 1 forest and 1 Malaysian Police Training Centre (PULAPOL). The selection of the study sites were based on the recent reports of leptospirosis outbreaks, exposure of human activity in nature and also invitation from government institutional. One hundred of rectangular wire traps were set up in the morning in each location from August 2008 until December 2009.

Kelantan: The traps were set up in October 2008 and April 2009 for 2 consecutive weeks at Etnobotani Training Camp, Gua Musang. Hundred traps were set near the trainees dorms, open field, canteen, along the lake and obstacle field. Kuala Betis, Gua Musang was the last place for the sampling site in Kelantan. The study took place in June 2009 for 1 week. Hundred traps were randomly placed along the road and waterfall area.

Terengganu: The trapping sites in Terengganu were inside Cheneh Cemerlang Training Camp, Kemaman and an oil palm plantation which situated near the camp. The traps were positioned the same as the camp site. Hundreds traps were set randomly in the oil palm plantation. Trapping of rats was carried out for 3 consecutive weeks started in October 2008 and finished in June 2009.

Malacca: In Malacca, rats were trapped in two places; Putra-Putri Training Camp and in an oil palm plantation. Both places were situated in Alor Gajah. The traps were placed inside and outside the camp due to low number of rats obtained inside the camp. Trapping of rats was carried out for 3 consecutive weeks started from November 2008 until July 2009.

Perak: The Royal Belum Rainforest was selected in this study as it contains various species of small mammals. The traps were set in August 2008 and March 2009. Hundred of traps were randomly placed in army camp, along the river (Tasik Banding) and in the aboriginal village. Pengkalan Hulu, Gerik is a small town in Perak and it was the last site for this study in Perak and trapping of rats were conducted in May 2009 and August 2009.

Selangor: In Selangor, the field work was conducted in PLKN Setia Ikhlas Camp in December 2009. Hundred of traps were placed for 1 week around the trainees' quarters, along the lake and in an open field.

Negeri Sembilan: The trapping site in Negeri Sembilan was carried out in PULAPOL Ayer Hitam which was situated in Jempol. Hundreds of traps were set randomly along the quarters, lake and open field with tall grass. The traps were set in September 2009.

Capture protocol: The rats were live-trapped using rectangular wire traps measuring $29 \times 22 \times 50 \mathrm{~cm}$. Baby banana or locally known as Pisang Emas (Musa acuminata musa) was used as bait. Rats found trapped inside the wire cage were removed and the traps were cleaned and added with fresh baits. All the trapped rats were euthanized humanely by placing each of them into a cloth bag containing cotton wool soaked with diethyl ether.

Identification of species: Animals were identified on the basis of their physical characteristics and body measurements; tail length, fur color, hind foot and ear length. The caught rats were also identified based on keys and illustrations established by Harrison and Quah (1962) which was helpful when identification by body measurement was uncertain.

Sample collection: Blood samples for serology were collected in a sterile anticoagulant-free vacutainer tube by cardiac puncture and allowed to clot at room temperature. Samples were transported on ice to the laboratory and sera were separated immediately by centrifugation of blood at $3,000 \times \mathrm{g}$ for $10 \mathrm{~min}$ at room temperature and were kept at $-20^{\circ} \mathrm{C}$ until the day of analysis.

The abdomen of each rat was cut opened and one kidney was removed aseptically and rinsed with distilled water. Then, the kidney is placed inside a barrel of a $5 \mathrm{~mL}$ syringe (without needle) and is compressed through the nozzle into a tube of culture medium. After standing at room temperature for $1-2 \mathrm{~h}, 0.5 \mathrm{~mL}$ of the supernatant is transferred into three bottles of fresh culture medium (Khairani-Bejo, 2001).

\section{Isolation of leptospires from kidney cultures}

Cultures: Semi-solid medium of EllinghausenMcCullough Johnson and Harris (EMJH) with addition of $200 \mu \mathrm{g} \mathrm{mL}^{-1} 5$-fluorouracil was used for isolation of leptospires from the kidneys (Faine et al., 1999). The cultures were incubated at $28-30^{\circ} \mathrm{C}$ up to 4 months and checked regularly for the presence of Dinger's disc. Positive culture was consecutively subcultured into fresh medium until a pure culture was obtained.

Microscopy: The morphological characters and motility of the isolates were examined under dark-field microscopy. Under dark-field microscope, leptospires were presented as thin, short, white and rotate rapidly on their axis. The 
growth of leptospires was examined once a week in the 1 st month, once in 2 weeks in the second and once in a month in the $3 \mathrm{rd}$ and 4 th months.

Identification of leptospiral isolates: Leptospiral isolates were identified by means of Polymerase Chain Reaction (PCR) assay. DNA was extracted from cultures of Leptospira with Wizard ${ }^{\text {TM }}$ Genomic DNA Purification kit (Promega) prior to amplification of DNA by primers 23S rRNA and 16S rRNA.

\section{Polymerase Chain Reaction (PCR) amplification} Detection by Genus-Specific Primers (23S rRNA): The primers used was genus-specific primers which were designed within the $r r l$ gene encoding $23 \mathrm{~S}$ rRNA thus the primers have no distinction between saprophytic and pathogenic strains (Leon et al., 2006). The primers were synthesized by Research Biolabs with the following sequences: F, 5'- GAC CCG AAG CCT GTC GAG -3' and $\mathrm{R}$, 5'-GCC ATG CTT AGT CCC GAT TAC-3'. Total 482 bp of PCR product was successfully generated by these primers. The method was performed as described by Leon et al. (2006). About $3 \mu \mathrm{L}$ of each sample was added in $0.2 \mathrm{~mL}$ PCR tube prior to the preparation of master mix. The PCR amplification was performed in a $1 \times \mathrm{PCR}$ buffer with $\mathrm{MgCl}_{2}$ at $1.5 \mathrm{mM}, 0.2 \mathrm{mM}$ each deoxynucleoside triphosphate (dATP, dTTP, dGTP and dUTP) purchased from Bioron $\mathrm{GmbH}, 0.2 \mathrm{mM}$ each primer and 1.0 U of DFS-Taq DNA polymerase (Bioron $\mathrm{GmbH}$ ). The reaction mixtures were performed in a DNA thermal cycler (Bio-Rad) for $5 \mathrm{~min}$ at $95^{\circ} \mathrm{C}$, they were subjected to 40 cycles of denaturation for $30 \mathrm{sec}$ at $94^{\circ} \mathrm{C}$, annealing for $1 \mathrm{~min}$ at $57^{\circ} \mathrm{C}$ and extension for $2 \mathrm{~min}$ at $72^{\circ} \mathrm{C}$. The final extension step was for $10 \mathrm{~min}$ at $72^{\circ} \mathrm{C}$.

Detection by pathogenic primers (16S rRNA): The $16 \mathrm{~S}$ rRNA primers are specific for pathogenic serovars (Shukla, 2003). The primers were synthesized by 1st BASE Oligonucleotide (Oligo) Synthesis with the following sequences: F, 5'-CGC TGG CGG CGC GTC TTA AA-3' and R, 5'-TTC ACC GCT ACA CCT GGA A-3'. Total 631 bp of PCR product was successfully generated by these primers. The method was performed as described by
Shukla (2003) however, there was some modification on its annealing temperature. Total $3 \mu \mathrm{L}$ of each sample was added in $0.2 \mathrm{~mL}$ PCR tube prior to the preparation of master mix. Reaction was performed in $25 \mu \mathrm{L}$ of total volume consist of $1 \times \mathrm{PCR}$ buffer with $\mathrm{MgCl}_{2}$ at $2.5 \mathrm{mM}$, $0.2 \mathrm{mM}$ each deoxynucleoside triphosphate (dATP, dTTP, dGTP and dUTP) purchased from Bioron $\mathrm{GmbH}, 5$ p moles of each primer and 1.0 U of DFS-Taq DNA polymerase (Bioron $\mathrm{GmbH}$ ). The PCR amplification with $16 \mathrm{~S}$ rRNA was performed in a DNA thermal cycler (Bio-Rad) using following steps: $3 \mathrm{~min}$ incubation at $94^{\circ} \mathrm{C}$ then was subjected to 35 cycles of denaturation for $1 \mathrm{~min}$ at $94^{\circ} \mathrm{C}$, annealing for $1 \mathrm{~min}$ at $61.3^{\circ} \mathrm{C}$ and extension for $2 \mathrm{~min}$ at $72^{\circ} \mathrm{C}$. The final extension step was for $10 \mathrm{~min}$ at $72^{\circ} \mathrm{C}$.

Agarose gel electrophoresis: About $5 \mu \mathrm{L}$ of Gel Loading Dye, Blue $(6 \times)$ purchased from New England BioLabs were well mixed with $25 \mu \mathrm{L}$ of PCR product. About $10 \mu \mathrm{L}$ of the mixture was subjected to electrophoresis on a $1.5 \%$ agarose gel in $1.5 \%$ Tris-Borate-buffer (TBE) at $70 \mathrm{~V}$ for $1 \mathrm{~h}$. The gel was prestained with ethidium bromide $\left(10 \mu \mathrm{g} \mathrm{mL}^{-1}\right.$ ) before loading of PCR products.

Statistical analysis: Calculations of statistical significance between groups were made by comparing proportions using the $\chi^{2}$-test. The SPSS for Windows, Version 16.0 (SPSS Inc.) Software was used to perform the calculations.

\section{RESULTS AND DISCUSSION}

Distribution of rats: Four hundred and eighty eight rats comprising eight species were successfully trapped from six states in Peninsular Malaysia from August 2008 until December 2009 (Table 1). Of the 488 trapped rats, 253 $(51.8 \%)$ were males and $235(48.2 \%)$ were females. Four hundred and fifty $(92.2 \%)$ rats were recorded as adults while the rest were sub adults and young rats, 5.3\% $(\mathrm{n}=26)$ and $2.5 \%(\mathrm{n}=12)$, respectively.

Terengganu: One hundred twenty eight $(26.2 \%)$ rats comprising three species were trapped in two distinct

Table 1: Composition of trapped rats and its morphological measurements

\begin{tabular}{|c|c|c|c|c|c|c|}
\hline Species & Total No. of animals (\%) & Weight (g) & $\mathrm{H}$ and $\mathrm{B}(\mathrm{mm})$ & $\mathrm{T}(\mathrm{mm})$ & $\mathrm{HF}(\mathrm{mm})$ & $\mathrm{E}(\mathrm{mm})$ \\
\hline R. tiomanicus & $420(86.0)$ & $30-224$ & $112-210$ & $80-213$ & $17-37$ & $15-30$ \\
\hline R. rattus diardi & $36(7.4)$ & 59-198 & $135-220$ & $85-213$ & $30-41$ & $18-28$ \\
\hline R. whiteheadi & $6(1.2)$ & $47-132$ & $125-177$ & $112-195$ & $23-34$ & $14-22$ \\
\hline M. rajah & $5(1.0)$ & $115-171$ & $175-192$ & $170-182$ & $38-41$ & $23-25$ \\
\hline R. argentiventer & $3(0.6)$ & $145-161$ & $160-225$ & $167-225$ & $32-50$ & $21-30$ \\
\hline R. exulans & $10(2.1)$ & $39-55$ & $130-138$ & $120-145$ & $27-28$ & $17-18$ \\
\hline R. muelleri & $6(1.2)$ & $178-386$ & $200-250$ & $235-300$ & $43-50$ & $21-25$ \\
\hline R. bowersi & $2(0.4)$ & $65-313$ & $160-225$ & $100-225$ & $45-50$ & $29-30$ \\
\hline
\end{tabular}

$\mathrm{H}$ and $\mathrm{B}$ : Head and Body, T: Tail, HF: Hind Foot, E: Ear 
locations; Cheneh Cemerlang Training Camp (NSTC) and an oil palm estate, both in Kemaman, Terengganu. Of these, $87(68.0 \%)$ rats comprising three species; $R$. argentiventer $(\mathrm{n}=2,2.3 \%), R$. rattus diardi $(\mathrm{n}=3,3.4 \%)$ and $R$. tiomanicus $(\mathrm{n}=82,94 \%)$ were trapped in Cheneh Cemerlang Training Camp (Table 2) followed by $41(32.0 \%)$ rats from species of $R$. tiomanicus were trapped in oil palm plantation (Table 3 ). The data indicated that $R$. tiomanicus which was also known as Malaysian wood rat constituted the dominant species trapped in both places as it commonly found living in scrub vegetation and plantation (Hafidzi and Saayon, 2001). Out of 128 trapped rats, sixty were males $(46.9 \%)$ and $68(53.1 \%)$ were females. One hundred twenty one $(94.5 \%)$ of the trapped rats were adults and the rest were sub adults $(n=2,1.6 \%)$ and young $(n=5,3.9 \%)$ rats.

Kelantan: Ninety rats (18.4\%) from four species were trapped in Etnobotani Training Camp and Kuala Betis in Gua Musang, Kelantan. Eighty one (90.0\%) rats consisting of $R$. tiomanicus $(\mathrm{n}=76,93.8 \%)$ and $M$. rajah ( $\mathrm{n}=5,6.2 \%$ ) were successfully trapped in Etnobotani Training Camp (Table 2) in October 2008 and April 2009. In Kuala Betis, three species of rats; $R$. muelleri ( $\mathrm{n}=4$, $44.4 \%), R$ tiomanicus $(\mathrm{n}=3,33.3 \%)$ and $R$. whiteheadi ( $\mathrm{n}=2,22.2 \%$ ) were trapped in June 2009 (Table 4). Out of
90 trapped rats, $47(52.2 \%)$ of the rats were males and $43(47.8 \%$ ) were females (Table 5). The number of trapped adults rats $(\mathrm{n}=84,93.3 \%$ ) was higher than sub adults $(\mathrm{n}=1,1.1 \%)$ and young rats $(\mathrm{n}=5,5.6 \%)$ (Table 6$)$.

Malacca: Five species of rats that made up of 111 rats were successfully trapped in two separate locations; Alor Gajah, Malacca; Putra-Putri Training Camp and oil palm estate. Sixty nine (62.2\%) rats were trapped in Putra-Putri Training Camp (Table 2 ) and the rest ( $\mathrm{n}=42,37.8 \%$ ) were from the oil palm estate (Table 3 ). Out of 111 trapped rats, $59(53.2 \%)$ were males and $52(46.8 \%)$ were females (Table 5). Four of the five species were trapped in PutraPutri Training Camp which comprised $R$. argentiventer $(\mathrm{n}=1,1.4 \%), R$. exulans $(\mathrm{n}=2,2.9 \%), R$. rattus diardi $(\mathrm{n}=12,17.4 \%)$ and $R$. tiomanicus $(\mathrm{n}=54,78.3 \%)$. Two rats from the species $R$. whiteheadi $(\mathrm{n}=2,4.8 \%)$ were found in oil palm plantation in Alor Gajah with $R$. tiomanicus $(\mathrm{n}=36,85.7 \%)$ and $R$ rattus diardi $(\mathrm{n}=4$, $9.5 \%$ ). Adults rats $(\mathrm{n}=107,96.4 \%)$ made up a major proportion of the trapped rats compared to sub adults $(\mathrm{n}=3,2.7 \%)$ and young rats $(\mathrm{n}=1,0.9 \%)($ Table 6$)$.

Perak: A total of $84(17.2 \%)$ rats comprising six species of rats were trapped from Royal Belum Rainforest and Pengkalan Hulu in Perak. Thirty one (36.9\%) of the

Table 2: Composition of rats in selected National Service Training Camp in Malaysia

\begin{tabular}{|c|c|c|c|c|c|c|c|}
\hline \multirow[b]{2}{*}{ NSTC } & \multirow[b]{2}{*}{ Rat species } & \multicolumn{2}{|l|}{ Sex } & \multirow{2}{*}{$\begin{array}{l}\text { Total No. of } \\
\text { animals (\%) }\end{array}$} & \multicolumn{3}{|l|}{ Age } \\
\hline & & Male & Female & & Adult & Sub-adult & Young \\
\hline \multirow[t]{4}{*}{ Terengganu } & R. argentiventer & 1 & 1 & $2(2.3)$ & 2 & 0 & 0 \\
\hline & R. rattus diordi & 0 & 3 & $3(3.4)$ & 3 & 0 & 0 \\
\hline & R. tiomonic us & 36 & 46 & $82(94.2)$ & 77 & 2 & 3 \\
\hline & No. of animals $(\%)$ & $37(42.5)$ & $50(57.5)$ & $87(68.0)$ & $82(94.3)$ & $2(2.3)$ & $3(3.4)$ \\
\hline \multirow[t]{3}{*}{ Kelantan } & $M$ rajah & 2 & 3 & $5(6.2)$ & 5 & 0 & 0 \\
\hline & R. tiomonic us & 42 & 34 & $76(93.8)$ & 72 & 1 & 3 \\
\hline & No. of animals (\%) & $44(54.3)$ & $37(45.7)$ & $81(90.0)$ & $77(95.1)$ & $1(1.2)$ & $3(3.7)$ \\
\hline \multirow[t]{5}{*}{ Malacca } & R. argentiventer & 0 & 1 & $1(1.4)$ & 1 & 0 & 0 \\
\hline & R. exulans & 2 & 0 & $2(2.9)$ & 2 & 0 & 0 \\
\hline & R. rattus diardi & 5 & 7 & $12(17.4)$ & 12 & 0 & 0 \\
\hline & R. tiomonic us & 28 & 26 & $54(78.3)$ & 53 & 1 & 0 \\
\hline & No. of animals (\%) & $35(50.7)$ & $34(49.3)$ & $69(62.2)$ & $68(98.6)$ & $1(1.4)$ & $0(0)$ \\
\hline \multirow[t]{4}{*}{ Selangor } & R. muelleri & 0 & 1 & $1(3.2)$ & 1 & 0 & 0 \\
\hline & R. rottus diardi & 3 & 3 & $6(19.4)$ & 6 & 0 & 0 \\
\hline & R. tiomanic us & 14 & 10 & $24(77.4)$ & 22 & 2 & 0 \\
\hline & No. of animals $(\%)$ & $17(54.8)$ & $14(45.2)$ & $31(100.0)$ & $29(93.5)$ & $2(6.5)$ & $0(0)$ \\
\hline
\end{tabular}

$\underline{\text { Table 3: Composition of rats in Oil Palm Estates in Terengganu and Malacca }}$

\begin{tabular}{|c|c|c|c|c|c|c|c|}
\hline \multirow[b]{2}{*}{ Oil palm estates } & \multirow[b]{2}{*}{ Rat species } & \multicolumn{2}{|l|}{ Sex } & \multirow{2}{*}{$\begin{array}{l}\text { Total No. of } \\
\text { animals }(\%)\end{array}$} & \multicolumn{3}{|l|}{ Age } \\
\hline & & Male & Female & & Adult & Sub-adult & Young \\
\hline \multirow[t]{2}{*}{ Terengganu } & R. tiomanic us & 20 & 21 & $41(100.0)$ & 39 & 0 & 2 \\
\hline & No. of animals $(\%)$ & $20(48.8)$ & $21(51.2)$ & $41(32.0)$ & $39(95.1)$ & $0(0)$ & $2(4.9)$ \\
\hline \multirow[t]{4}{*}{ Malacca } & R. rattus diardi & 2 & 2 & $4(9.5)$ & 3 & 1 & 0 \\
\hline & R. tiomanicus & 21 & 15 & $36(85.7)$ & 34 & 1 & 1 \\
\hline & R. whitehe adi & 1 & 1 & $2(4.8)$ & 2 & 0 & 0 \\
\hline & No. of animals (\%) & $24(57.1)$ & $18(42.9)$ & $42(37.8)$ & $39(92.8)$ & $2(4.8)$ & $1(2.4)$ \\
\hline
\end{tabular}


Res. J. Anim. Sci., 6 (1): 12-25, 2012

\begin{tabular}{|c|c|c|c|c|c|c|c|}
\hline \multirow[b]{2}{*}{ Suburban } & \multirow[b]{2}{*}{ Rat species } & \multicolumn{2}{|l|}{ Sex } & \multirow{2}{*}{$\begin{array}{l}\text { Total No. of } \\
\text { animals }(\%)\end{array}$} & \multicolumn{3}{|l|}{ Age } \\
\hline & & Male & Female & & Adult & Sub-adult & Young \\
\hline \multirow[t]{5}{*}{ Pengkalan Hulu Perak } & R. bowersi & 1 & 1 & $2(3.8)$ & 1 & 0 & 1 \\
\hline & R. rattus diardi & 1 & 1 & $2(3.8)$ & 2 & 0 & 0 \\
\hline & R. tiomanicus & 25 & 23 & $48(90.5)$ & 43 & 5 & 0 \\
\hline & R. muelleri & 0 & 1 & $1(1.9)$ & 1 & 0 & 0 \\
\hline & No. of animals (\%) & $27(50.9)$ & $26(49.1)$ & $53(63.1)$ & $47(88.7)$ & $5(9.4)$ & $1(1.9)$ \\
\hline \multirow[t]{4}{*}{ Kuala Betis Kelantan } & R. tiomanicus & 0 & 3 & $3(33.3)$ & 3 & 0 & 0 \\
\hline & R. muelleri & 2 & 2 & $4(44.4)$ & 4 & 0 & 0 \\
\hline & R. whiteheadi & 1 & 1 & $2(22.2)$ & 0 & 0 & 2 \\
\hline & No. of animals (\%) & $3(33.3)$ & $6(66.7)$ & $9(10.7)$ & $7(77.8)$ & $0(0)$ & $2(22.2)$ \\
\hline
\end{tabular}

\begin{tabular}{|c|c|c|c|c|c|c|c|c|c|c|c|c|c|c|}
\hline \multirow[b]{2}{*}{ Species } & \multicolumn{2}{|c|}{ Terengganu } & \multicolumn{2}{|c|}{ Kelantan } & \multicolumn{2}{|c|}{ Malacca } & \multicolumn{2}{|l|}{ Perak } & \multicolumn{2}{|c|}{ Negeri Sembilan } & \multicolumn{2}{|c|}{ Selangor } & \multicolumn{2}{|l|}{ Total } \\
\hline & Male & Female & Male & Female & Male & Female & Male & Female & Male & Female & Male & Female & Male & Female \\
\hline R. tiomanicus & 56 & 67 & 42 & 37 & 49 & 41 & 33 & 27 & 20 & 24 & 14 & 10 & 214 & 206 \\
\hline R. rattus diardi & 3 & 0 & 0 & 0 & 7 & 9 & 10 & 1 & 0 & 0 & 3 & 3 & 23 & 13 \\
\hline R. whiteheadi & 0 & 0 & 1 & 1 & 1 & 1 & 1 & 1 & 0 & 0 & 0 & 0 & 3 & 3 \\
\hline M. rajah & 0 & 0 & 2 & 3 & 0 & 0 & 0 & 0 & 0 & 0 & 0 & 0 & 2 & 3 \\
\hline R. argentiventer & 1 & 1 & 0 & 0 & 0 & 1 & 0 & 0 & 0 & 0 & 0 & 0 & 1 & 2 \\
\hline R. exulans & 0 & 0 & 0 & 0 & 2 & 0 & 5 & 3 & 0 & 0 & 0 & 0 & 7 & 3 \\
\hline R. mueleri & 0 & 0 & 2 & 2 & 0 & 0 & 0 & 1 & 0 & 0 & 0 & 1 & 2 & 4 \\
\hline R. bowersi & 0 & 0 & 0 & 0 & 0 & 0 & 1 & 1 & 0 & 0 & 0 & 0 & 1 & 1 \\
\hline Total & 60 & 68 & 47 & 43 & 59 & 52 & 50 & 34 & 20 & 24 & 17 & 14 & 253 & 235 \\
\hline
\end{tabular}

Table 6: Distribution of rats in each state according to age

\begin{tabular}{|c|c|c|c|c|c|}
\hline \multirow[b]{2}{*}{$\underline{\text { State }}$} & \multirow[b]{2}{*}{ Species } & \multicolumn{4}{|l|}{ Age } \\
\hline & & Adult & Sub-adult & Young & Total \\
\hline \multirow[t]{5}{*}{ Kelantan } & R. tiomanicus & 75 & 1 & 3 & 79 \\
\hline & M rajah & 5 & 0 & 0 & 5 \\
\hline & R. whitehe adi & 0 & 0 & 2 & 2 \\
\hline & R. muelleri & 4 & 0 & 0 & 4 \\
\hline & Total & 84 & 1 & 5 & 90 \\
\hline \multirow[t]{6}{*}{ Malacca } & R. tiomanic us & 87 & 2 & 1 & 90 \\
\hline & R. rattus diardi & 15 & 1 & 0 & 16 \\
\hline & R. exulons & 2 & 0 & 0 & 2 \\
\hline & R. argentiventer & 1 & 0 & 0 & 1 \\
\hline & R. whitehe adi & 2 & 0 & 0 & 2 \\
\hline & Total & 107 & 3 & 1 & 111 \\
\hline \multirow[t]{2}{*}{ Negeri Sembilan } & R. tiomanicus & 31 & 13 & 0 & 44 \\
\hline & Total & 31 & 13 & 0 & 44 \\
\hline \multirow[t]{7}{*}{ Perak } & R. tiomanicus & 55 & 5 & 0 & 59 \\
\hline & R. rattus diardi & 11 & 0 & 0 & 11 \\
\hline & R. exulons & 8 & 0 & 0 & 8 \\
\hline & R. whitehe adi & 2 & 0 & 0 & 2 \\
\hline & R. bowersi & 1 & 0 & 1 & 2 \\
\hline & R. muelleri & 1 & 0 & 0 & 1 \\
\hline & Total & 78 & 5 & 1 & 84 \\
\hline \multirow[t]{4}{*}{ Selangor } & R. tiomanicus & 22 & 2 & 0 & 24 \\
\hline & R. rattus diardi & 6 & 0 & 0 & 6 \\
\hline & R. muelleri & 1 & 0 & 0 & 1 \\
\hline & Total & 29 & 2 & 0 & 31 \\
\hline \multirow[t]{5}{*}{ Terengganu } & R. tiomanicus & 116 & 2 & 5 & 123 \\
\hline & R. rattus diardi & 3 & 0 & 0 & 3 \\
\hline & R. argentiventer & 2 & 0 & 0 & 2 \\
\hline & Total & 121 & 2 & 5 & 128 \\
\hline & Grand total & 450 & 26 & 12 & 488 \\
\hline
\end{tabular}

trapped rats was from Royal Belum Rainforest and the rest were from Pengkalan Hulu. Four species of rats belonging to $R$. whiteheadi $(2 / 31,6.5 \%), R$. exulans $(8 / 31,25.8 \%)$, $R$. rattus diardi $(9 / 31,29.0 \%)$ and $R$. tiomanicus $(12 / 31$, $38.7 \%$ ) were trapped from Royal Belum Rainforest
(Table 7) in August, 2008 and March, 2009. R. tiomanicus $(48 / 53,90.5 \%)$ was the dominant species found in Pengkalan Hulu compared to R. bowersi $(\mathrm{n}=2,3.8 \%)$, $R$. rattus diardi $(\mathrm{n}=2,3.8 \%)$ and $R$. muelleri $(\mathrm{n}=1,1.9 \%)$. $R$. muelleri was the biggest species of rat recorded (Table 1) weighing about $386 \mathrm{~g}$ and measuring about $250 \mathrm{~mm}$ from head to body. From the total number of rats, $78(92.8 \%)$ rats were adults and the rest were sub adults $(\mathrm{n}=5,6.0 \%)$ and young $(\mathrm{n}=1,1.2 \%)$ rats.

Negeri Sembilan: $R$. tiomanicus was the only species trapped in PULAPOL (The Malaysian Police Training Centre) Ayer Hitam, Negeri Sembilan (Table 8). A total of 44 rats comprising $20(45.4 \%)$ males and $24(54.5 \%)$ females were trapped from scrub vegetation and secondary forest. Adult rats $(\mathrm{n}=31,70.5 \%)$ formed a major proportion compared to sub adult rats $(\mathrm{n}=13$, $29.5 \%)$.

Selangor: Thirty one (6.4\%) rats comprising three species were trapped in PLKN Setia Ikhlas Camp, Semenyih Selangor in December 2009. The trapped rats were R. muelleri $(\mathrm{n}=1,3.2 \%)$, $R$. rattus diardi $(\mathrm{n}=6,19.4 \%)$ and $R$. tiomanicus $(\mathrm{n}=24,77.4 \%)$. The number of trapped adults rats $(\mathrm{n}=29,93.35 \%)$ was higher than sub adults $(\mathrm{n}=2,6.5 \%)$ rats.

Bacteriology: From Table 9, 60 (12.3\%) leptospiral isolates were cultured from 488 kidneys of rats. Of these, $24(18.8 \%)$ isolates were obtained from Terengganu followed by Kelantan $(\mathrm{n}=13,14.4 \%)$, Malacca $(\mathrm{n}=13$, 
Res. J. Anim. Sci., 6 (1): 12-25, 2012

Table 7: Composition of rats in Royal Belum Rainforest

\begin{tabular}{|c|c|c|c|c|c|c|c|}
\hline \multirow[b]{2}{*}{ Forest } & \multirow[b]{2}{*}{ Rat species } & \multicolumn{2}{|l|}{ Sex } & \multirow{2}{*}{$\begin{array}{l}\text { Total No. of } \\
\text { animals (\%) }\end{array}$} & \multicolumn{3}{|l|}{ Age } \\
\hline & & Male & Female & & Adult & Sub-adult & Young \\
\hline \multirow[t]{5}{*}{ Royal Belum } & R. whiteheadi & 1 & 1 & $2(6.45)$ & 2 & 0 & 0 \\
\hline & R. exulans & 5 & 3 & $8(25.80)$ & 8 & 0 & 0 \\
\hline & R. rattus diardi & 10 & 0 & $10(32.20)$ & 10 & 0 & 0 \\
\hline & R. tiomanicus & 7 & 4 & $11(35.50)$ & 11 & 0 & 0 \\
\hline & No. of animals (\%) & $23(73.3)$ & $8(26.7)$ & $31(36.10)$ & $31(100)$ & $0(0)$ & $0(0)$ \\
\hline
\end{tabular}

Table 8: Composition of rats in PULAPOL Ayer Hitam, Negeri Sembilan

\begin{tabular}{|c|c|c|c|c|c|c|c|}
\hline \multirow[b]{2}{*}{ PULAPOL } & \multirow[b]{2}{*}{ Rat species } & \multicolumn{2}{|l|}{ Sex } & \multirow{2}{*}{$\begin{array}{l}\text { Total no. of } \\
\text { animals }(\%)\end{array}$} & \multicolumn{3}{|l|}{ Age } \\
\hline & & Male & Female & & Adult & Sub-adult & Young \\
\hline Ayer Hitam & $\begin{array}{l}\text { R. tiomanicus } \\
\text { No. of animals (\%) }\end{array}$ & $\begin{array}{l}20 \\
20(45.4)\end{array}$ & $\begin{array}{l}24 \\
24(54.5)\end{array}$ & $\begin{array}{l}44 \\
44(100.0)\end{array}$ & $\begin{array}{l}31 \\
31(70.5)\end{array}$ & $\begin{array}{l}13 \\
13(29.5)\end{array}$ & $\begin{array}{l}0 \\
0(0)\end{array}$ \\
\hline
\end{tabular}

Table 9: Number of isolates positive for primers 23S rRNA and 16S rRNA for each state

\begin{tabular}{|c|c|c|c|c|c|c|}
\hline State & $\begin{array}{l}\text { No. of } \\
\text { cultures }\end{array}$ & $\begin{array}{l}\text { No. of } \\
\text { positive } \\
\text { cultures }\end{array}$ & $\begin{array}{l}23 \mathrm{~S} \\
\text { rRNA }\end{array}$ & $\%$ & $\begin{array}{l}16 \mathrm{~S} \\
\text { rRNA }\end{array}$ & $\%$ \\
\hline Kelantan & 90 & 13 & 13 & 14.4 & 10 & 10.0 \\
\hline Terengganu & 128 & 24 & 24 & 18.8 & 20 & 15.6 \\
\hline Malacca & 111 & 13 & 13 & 11.7 & 7 & 6.3 \\
\hline Perak & 84 & 5 & 5 & 6.0 & 3 & 3.6 \\
\hline Negeri Sembilan & 44 & 5 & 5 & 11.4 & 2 & 4.5 \\
\hline Selangor & 31 & 0 & 0 & 0.0 & 0 & 0.0 \\
\hline Total & 488 & 60 & 60 & 12.3 & 42 & 8.6 \\
\hline
\end{tabular}

11.7\%), Negeri Sembilan $(n=5,11.4 \%)$ and Perak $(n=5$, $6.0 \%)$. Fifty one isolates $(10.5 \%)$ were cultured from kidneys of $R$. tiomanicus with $18.0 \%(\mathrm{n}=23)$ of the isolates were obtained from Terengganu. $R$. rattus diardi had 8.3\% (n=5) cultures positive for leptospires followed by $R$. exulans $(3.3 \%, \mathrm{n}=2)$. Only one $(1.6 \%)$ isolate was obtained from $R$. argentiventer and $R$. whiteheadi. Adult rats $(\mathrm{n}=54,90 \%)$ gave major proportions of the isolates compared to sub adults $(\mathrm{n}=4,6.6 \%)$ and young $(\mathrm{n}=2$, $3.3 \%)$ rats. Male rats contributed to $60 \%(n=36)$ of the total isolates whilst female rats $(\mathrm{n}=24,40 \%)$. No isolate was obtained from the rats in Selangor.

Detection of leptospiral DNA with genus-specific and pathogenic primers: All sixty isolates $(12.3 \%)$ were successfully amplified by genus-specific primers $(23 \mathrm{~S}$ rRNA) (Fig. 1) thus confirmed all isolates as Leptospira. However, 16S rRNA primers were able to detect only 42 $(8.6 \%)$ isolates as pathogenic Leptospira. Statistical analysis indicates carrier rates were significantly different for each state ( $p>0.001)$. The number of amplifiable DNA by both primers in Terengganu exceeds the other states (Table 9). Twenty (15.6\%) of the isolates from Terengganu were amplified by pathogenic 16S rRNA primers and the rest $(\mathrm{n}=24,18.8 \%)$ by genus-specific primers. Nine $(10.0 \%)$ of the 13 isolates from Kelantan were detected as pathogenic leptospires (Fig. 2). Isolates from Malacca showed $7(6.3 \%)$ out of 13 isolates were positive as pathogenic leptospires. Five isolates from Perak (6.0\%)

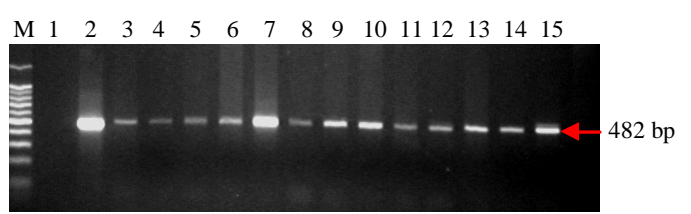

Fig. 1: Agarose gel electrophoresis showing PCR products amplified by primers $23 \mathrm{~S}$ rRNA; Lane M: DNA size marker, 100 bp DNA ladder; Lane 1: Negative control; Lane 2: Positive control ( $L$. interrogans serovar icterohaemorrhagiae); Lane 3-15: Samples of cultured kidneys

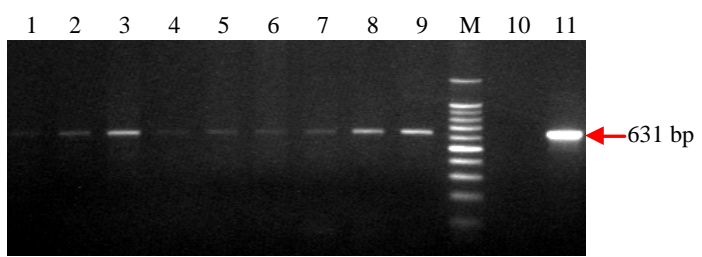

Fig. 2: Agarose gel electrophoresis showing PCR products amplified by primers $16 \mathrm{~S}$ rRNA; Lane M: DNA size marker, 100 bp DNA ladder; Lane 10: Negative control; Lane 11: Positive control ( $L$. interrogans serovar icterohaemorrhagiae); Lane 1- 9: Samples of cultured kidneys

and Negeri Sembilan (11.4\%) were able to be amplified by genus specific primers and gave only $3.6 \%(\mathrm{n}=3)$ and $4.5 \%(\mathrm{n}=2)$ pathogenic leptospires of respective states.

A significant difference in carrier rates was observed in each habitat $(\mathrm{p}>0.001)$. Four Training Camps (NSTC) contributed to the highest number $(\mathrm{n}=35,13.1 \%)$ of pathogenic leptospires from 268 cultured kidneys as detected by $16 \mathrm{~S}$ rRNA primers (Table 10). The oil palm estates (2.4\%), PULAPOL (4.5\%) and forest habitat (6.7\%) only gave two pathogenic Leptospira isolates from the 
samples collected from each habitat. Suburban area only showed one (1.6\%) pathogenic Leptospira isolate from a total of 60 cultured kidneys.

\section{Infection rates in captured rats}

Species: Pathogenic leptospires were detected in four species of rats collected from different states (Table 11). The species of rats were $R$. tiomanicus, $R$. exulans, $R$. rattus diardi and $R$. argentiventer. Thirty seven (7.6\%) of the isolates belonged to species $R$. tiomanicus $(\mathrm{n}=420)$. Two pathogenic leptospires were obtained from $R$. exulans $(0.4 \%)$ and $R$. rattus diardi $(0.4 \%)$. One $(0.2 \%)$ out of three cultured kidneys from $R$. argentiventer was positive for pathogenic Leptospira.

Sex: Table 12 shows the number of infected males and females for each species of rats. The total number of carrier animals was slightly higher in male rats $(9.5 \%)$ than those of female rats $(7.6 \%)$. The number of infected males

Table 10: Number of isolates positive for the set of primers 23S rRNA and $16 \mathrm{~S}$ rRNA in each habitat

\begin{tabular}{|c|c|c|c|c|c|c|}
\hline Habitat & State & $\begin{array}{l}\text { No. of } \\
\text { cultures }\end{array}$ & $\begin{array}{c}23 \mathrm{~S} \\
\text { rRNA }\end{array}$ & $\%$ & $\begin{array}{l}16 \mathrm{~S} \\
\text { rRNA }\end{array}$ & $\%$ \\
\hline Oil palm & Malacca, Terengganu & 83 & 3 & 3.6 & 2 & 2.4 \\
\hline NSTC & $\begin{array}{l}\text { Kelantan, Terengganu } \\
\text { Malacca and Selangor }\end{array}$ & 268 & 46 & 17.2 & 35 & 13.1 \\
\hline PULAPOL & Negeri Sembilan & 44 & 5 & 13.6 & 2 & 4.5 \\
\hline Suburban & Perak and Kelantan & 62 & 2 & 3.2 & 1 & 1.6 \\
\hline \multirow[t]{2}{*}{ Forest } & Perak & 31 & 4 & 13.3 & 2 & 6.7 \\
\hline & Total & 488 & 60 & 12.3 & 42 & 8.4 \\
\hline
\end{tabular}

Table 11: Number of pathogenic leptospiral isolates according to rat species PCR

\begin{tabular}{lcc} 
Species & No. of samples examined & Positive (\%) \\
\hline R. tiomanicus & 420 & $37(7.6)$ \\
R. rattus diardi & 36 & $2(0.4)$ \\
R. exulans & 10 & $2(0.4)$ \\
R. argentiventer & 3 & $1(0.2)$ \\
M. rajah & 5 & 0 \\
R. whiteheadi & 6 & 0 \\
R. bowersi & 2 & 0 \\
R. muelleri & 6 & 0 \\
Total & 488 & $42(8.6)$ \\
\hline
\end{tabular}

Table 12: Distribution of pathogenic leptospiral isolates based on sex for each rat species

\begin{tabular}{|c|c|c|c|c|}
\hline \multirow[b]{2}{*}{ Species } & \multicolumn{2}{|l|}{ Male } & \multicolumn{2}{|l|}{ Female } \\
\hline & No. examined & No. pos $(\%)$ & No. examined & No. pos $(\%)$ \\
\hline R. tiomanicus & 214 & $21(8.3)$ & 206 & $16(6.8)$ \\
\hline R. rattus diardi & 23 & $1(0.4)$ & 13 & $1(0.4)$ \\
\hline R. argentiventer & 1 & 0 & 2 & $1(0.4)$ \\
\hline R. exulans & 7 & $2(0.8)$ & 3 & 0 \\
\hline M. rajah & 2 & 0 & 3 & 0 \\
\hline R. whiteheadi & 3 & 0 & 3 & 0 \\
\hline R. muelleri & 2 & 0 & 4 & 0 \\
\hline R. bowersi & 1 & 0 & 1 & 0 \\
\hline Total (\%) & $253(51.8 \%)$ & $24(9.5)$ & $235(48.2 \%)$ & $18(7.6)$ \\
\hline
\end{tabular}

from species $R$. tiomanicus exceeds those of female rats. However, there was no significant relationship observed between sexes of rats to the carrier rates $(p>0.05)$.

Age: There was no significant relationship between age-classes and carrier rate $(\mathrm{p}>0.05)$ as chronic infection prevailed in adult rats $(38 / 488,7.8 \%)$ than those of the sub adult $(3 / 488,0.6 \%)$ or young $(1 / 488,0.2 \%)$ rats.

Characteristics of carrier rats in each habitat: R. tiomanicus was the common species of rats that carried pathogenic Leptospira in National Service Training Camp, NSTC (11.9\%) compared to $R$. rattus diardi $(9.5 \%)$ and $R$. argentiventer $(0.4 \%)$. Two pathogenic leptospires obtained from oil palm estate, PULAPOL and forest habitat belonged to $R$. tiomanicus (Oil palm estates and PULAPOL) and $R$. exulans (forest). One pathogenic leptospiral isolate obtained from suburban area was from R. tiomanicus.

Total $33(12.3 \%)$ of carrier rats in NSTC were adults and the rest were sub adult $(\mathrm{n}=1,0.4 \%)$ and young $(\mathrm{n}=1,0.4 \%)$ rats. All carrier rats in forest habitat, oil palm estate and suburban were adults. Carrier rats from PULAPOL were identified as sub adults. According to sexes, the number of carrier rats in NSTC was higher in males $(n=19,7.1 \%)$ than those of female rats $(n=16$, $6.0 \%$ ). Carrier rats from forest habitat, PULAPOL and suburban were identified as males and vice versa for carrier rats from oil palm estate (Table 13).

Information on the distribution of rodent in any area is useful because rodents are known to be involved in the transmission of diseases to humans and domestic animals (Battersby and Greenwood, 2004) and they are reservoir for a number of parasites, plague and other pathogens (Zahedi et al., 1984). Relative abundance of the individual rat species in a habitat is relied on their ability to adapt and exploit new environments rapidly. In this study, distribution of eight species of rats was significantly different in the five selected places $(\mathrm{p}<0.05)$. Among these rat species, $R$. tiomanicus was the dominant species trapped in all localities studied and it accounted for $85.4 \%(n=420)$ of the total trapped rats (Table 1). In the agricultural sector, R. tiomanicus is recognized as the principal domestic pest in oil palm estates in which they feed on developing fruit bunches and commonly build nests in the piles of old fronds cut from the palms or in the crowns (Wood, 2001). The arboreal habits of $R$. tiomanicus was the main factor contributed to the domination in mature oil palm plantation (Wood, 1982). 
Res. J. Anim. Sci., 6 (1): 12-25, 2012

Table 13: Characteristics of carrier rats in five habitats

\begin{tabular}{|c|c|c|c|c|c|}
\hline \multirow[b]{2}{*}{ Characteristics } & \multicolumn{5}{|c|}{ No. of positive/total (\%) } \\
\hline & Forest & NSTC & Oil palm estates & PULAPOL & Suburban areas \\
\hline \multicolumn{6}{|l|}{ Species } \\
\hline R. tiomanicus & $0 / 12(0)$ & $32 / 236(13.6)$ & $2 / 77(2.6)$ & $2 / 44(4.5)$ & $1 / 51(2.0)$ \\
\hline R. rattus diordi & $0 / 9(0)$ & $2 / 21(0.7)$ & $0 / 4(0)$ & - & $0 / 2(0)$ \\
\hline R. exulans & $2 / 8(25)$ & $0 / 2(0)$ & - & - & - \\
\hline R. whiteheadi & $0 / 2(0)$ & - & $0 / 2(0)$ & - & $0 / 2(0)$ \\
\hline R. argentiventer & - & $1 / 3(0.4)$ & - & - & - \\
\hline M. rajah & - & $0 / 5(0)$ & - & - & - \\
\hline R. muelleri & - & $0 / 1(0)$ & - & - & $0 / 5(0)$ \\
\hline R. bowersi & - & & - & - & $0 / 2(0)$ \\
\hline Total & $2(6.5)$ & $35(13.1)$ & $2(2.4)$ & $2(4.5)$ & $1(1.6)$ \\
\hline \multicolumn{6}{|l|}{ Age } \\
\hline Adult & $2(6.5)$ & $33(12.3)$ & $2(2.4)$ & - & $1(1.6)$ \\
\hline Subadult & - & $1(0.4)$ & - & $2(4.5)$ & - \\
\hline Young & - & $1(0.4)$ & - & - & - \\
\hline \multicolumn{6}{|l|}{ Sex } \\
\hline Female & - & 16 & 2 & - & - \\
\hline Male & 2 & 19 & - & 2 & 1 \\
\hline Total No. of rats (\%) & $31(6.4)$ & $268(54.9)$ & $83(17.0)$ & $44(9.0)$ & $62(12.7)$ \\
\hline
\end{tabular}

In areas other than the agricultural sector, $R$. tiomanicus was observed to live under scrub vegetation and in places where garbage dump is presence. Such features could be seen in training camps including NSTC and PULAPOL. Besides, the presence of garbage dumps in both camps increased infestation of rats particularly $R$. tiomanicus due to the availability of food and shelter. Food, being the foremost of their requirement, they are likely to be found near places where the supply of it is in abundant and of easy access. Accumulation of waste sites was recorded in Rio de Janeiro to be the main factor for the infestation of rats in the area (Barcellos and Sabroza, 2001). The huge number of rats trapped in such areas could be due to the presence of all sources required for the sustenance of rats, this include the availability of training ponds for outdoor activities as their water source. Therefore, limitations on food, water or harborage are the determinants to the size of a community's rat population.

Forests in Southeast Asia are characterized by flowering and fruit production which significantly contributed to the abundance and population increase of rodents including rats from the Muridae family (Nakagawa et al., 2007). Study conducted in Royal Belum Rainforest came up with four species; $R$. tiomanicus, $R$. rattus diardii, $R$. exulans and $R$. whiteheadi (Table 7). $R$. tiomanicus, $R$. exulans and $R$. whiteheadi have been recorded in secondary forests at elevation of $<1,000 \mathrm{~m}$ (Mohamad, 1992). The presence of $R$. rattus diardi in Royal Belum Rainforest which commonly live in closer proximity to humans could be explained by the presence of temporal house built for hikers, military personnel and tourists. The presence of leftover food and food wrapper would attract $R$. rattus diardi to inhabit the place. The changes in the forest rodent population were the results from the increased frequency of human activities into the forest.

Poor drainage and lack of sanitation lead to the infestation of rats in suburban environment. In a study conducted by Battersby et al. (2002), he disclosed a huge number $R$. norvegicus that carried multiple etiological agents in United Kingdom urban environment which was linked to poor areas of housing. There were four species of rats observed in Pengkalan Hulu; $R$. tiomanicus, $R$. bowersi, $R$. rattus diardi and $R$. muelleri. Among those species, $R$. rattus diardi is recognized as the principal pest in urban environment and commonly seen nesting in bushes near human habitation and in field (Harrison, 1957). However, $R$. tiomanicus which was normally found in agricultural areas (Hafidzi and Saayon, 2001) was observed to occupy the place which explained the huge number of respective rats trapped (Table 4). The accumulation of junk and rubbish in residential areas and commercial premises provides rats with the shelter they require to survive. It consists of abandoned automobiles; abandoned appliances, lumber and wood on the ground. The presence of $R$. bowersi in Pengkalan Hulu could be due to the traps that were set up along the streams which connected to the foothills nearby. This species is known to inhabit hilly forest at elevation above $750 \mathrm{~m}$ (Mohamad, 1992).

PULAPOL Ayer Hitam was an ideal habitat for $R$. tiomanicus. This is strongly indicated by the presence of the species which belongs to $R$. tiomanicus (Table 8). The traps that were set up in grassland and bushes would contribute to the capture of $R$. tiomanicus as it known to inhabit such places (Mohamad, 1992). Poor housing area 
may serve as shelter for rats. On the other hand, pond and open refuse dump provide water and food source which increase rat infestation in that area.

Culture is more sensitive than PCR assay in terms of the number of leptospiral isolates detected under dark-field microscope (Table 9). The degree of success attained in isolating leptospires is influenced by a few factors such as the medium used, the number of inoculation made and the length of time for which the culture are kept (Ellis, 1986). It was found that the incorporation of 5-FU as a selective agent for isolation of leptospires in $\mathrm{EMJH}$ medium is effective in controlling bacteria contaminants without affecting the survival of leptospires (Faine et al., 1999). The following characteristics were used to determine leptospires microscopically; spiral, thin with hook at both ends (Bharti et al., 2003). Further confirmation is needed in which leptospires were discriminated from other bacteria. Hence, PCR assay is suited to the need for reliable and rapid detection of Leptospira from various sources. PCR is reliable and specific than culture technique due to the use of specific primers which derived from Leptospira gene (Shukla, 2003).

Polymerase Chain Reaction (PCR) analysis is increasingly used for the diagnosis of leptospires from various specimens. Several PCR techniques have been developed for rapid detection of leptospiral isolates seen in clinical samples (urine, cerebrospinal fluid, blood or tissues) from animals or humans (Merien et al., 1992). Primers have been designated from certain gene that allow detection of Leptospira at genus (Gravekamp et al., 1993), species (Reitstetter, 2006) and serovar (Ramadass et al., 2002) level. Some primers were able to differentiate between pathogenic and saprophytic leptospires (Leon et al., 2006).

The 23S rRNA primers used in this study yielded a product of the expected size (482 bp) from cultured kidneys. These primers were designed within the $r r l$ gene encoding $23 \mathrm{~S}$ rRNA and were expected to amplify leptospiral DNA without any distinction between saprophytic and pathogenic strains. Figure 1 (Lanes 3-15) demonstrating the presence of bacteria belonging to the Leptospira at genus level as confirmed by reference strain (RGA) at Lane 2. These primers were able to detect leptospires from foal's tissue as reported by Leon et al. (2006). Detection of leptospires at genus level is useful for screening large numbers of samples in which only samples which positive for $23 \mathrm{~S}$ rRNA primers will be proceed for testing with pathogenic primers.

The 16S rRNA primers yielded a positive PCR signal of size $631 \mathrm{bp}$ for the pathogenic Leptospira strain used as a control (Fig. 2, Lane 11). This result confirmed positive isolates as been detected by the $23 \mathrm{~S}$ rRNA primers were pathogenic leptospires (Fig. 2, Lanes 1-9). These primers were derived from $16 S r R N A$ gene encoding $16 \mathrm{~S}$ rRNA and were expected to amplify pathogenic leptospiral DNA (Shukla, 2003). These primers are powerful in discriminating pathogenic leptospires on leptospiral DNA positive at genus level. The combination of primers is useful in epidemiological study for detection of leptospiral DNA from large number of samples.

Regarding the positive cultures for leptospires that were negative by PCR (Table 9), there are several factors that might help to explain these confounding results. Some of the cultures were heavily contaminated with other bacteria. The presence of inhibitors in the cultures may intervene the PCR reaction which could result in false-negative result (Weyant et al., 1990). Some leptospiral serovars are fastidious and required complicated nutritional requirements and often fail to grow in culture medium, therefore, variability is expected when bacterial culture is used as a source of DNA for the PCR.

Identification of pathogenic leptospires is important in order to identify the reservoirs and animal sources associated with human infections. Identification of Leptospira by PCR is rapid and can help researchers to recognize the source of infection in leptospirosis outbreaks and more useful than serological tests which were laborious, intensive and slow. However, the disadvantage of PCR assay is its inability to assign a Leptospira serovar.

Many human infections were from animals. For some of these, the source of infection is wildlife. Leptospirosis is considered to be the most common zoonosis in the world and rodents which represent $40 \%$ of mammalian species (Wilson and Reeder, 2005) have been noticed as the most important and widely distributed reservoir. In reservoir animals, leptospires persist in immunologically favored sites such as renal tubules (Barnett et al., 1999; Athanazio et al., 2008). Kidney involvement in many animals including rats (Matthias et al., 2008) is chronic in nature and results in shedding of large number of leptospires in the urine (Faine et al., 1999).

It was recorded that 37 out of the 42 leptospiral isolates $(88.1 \%)$ were isolated from $R$. tiomanicus. The role of $R$. tiomanicus as carrier for leptospires could be explained by its wide distribution in various habitats in Malaysia. The abundance of $R$. tiomanicus overrides other rat species in terms of carriage rates (Table 11). In Brazil, the higher population density of $R$. norvegicus was the main factor that facilitates transmission of leptospirosis within rat population (Faria et al., 2008). Previously, the same species was documented to be the 
main reservoir for serovar copenhageni worldwide (Faine et al., 1999). Other species of rats can be infected from one another as they favor and share the same tracks in their environment. The risk for zoonotic diseases is directly related to reservoir population density as the probability of human contact with infected rodents increased (Davis et al., 2005). Fluctuation in rodent population is controlled by factors such as food supply and habitat quality (Mills and Childs, 1998).

Leptospiral infections are maintained within rat population through vertical and horizontal transmission (Faine et al., 1999). Associations of renal colonization with age suggesting horizontal (rather than vertical) transmission as adult rats were more likely to harbor pathogenic leptospires compared to sub adults or young rats (Table 13). This was in agreement with previous reports that showed mature urban $R$. rattus are four times more likely to carry leptospires than immature $R$. rattus and probably reflects an increased probability of encountering pathogens with age (Carter and Cordes, 1980). Fighting and biting among adult rats may be a common mechanism that facilitates leptospiral transmission as leptospires from urine-contaminated water or soil are able to penetrate broken or wound skin. Moreover, only the adult class is able to reproduce and hence transmission via sexual contact only applies to this age-class. Young rats are generally confined to the nest and susceptible young rats not being exposed to free-living leptospires.

Based on sexual-classes, male rats exhibited slightly higher renal colonization $(9.5 \%, 24 / 253)$ compared to female rats $(7.6 \%, 18 / 235)$. Statistically, the number of carrier male rats was not significantly differed to that seen in female rats $(p>0.05)$. The absence of sex differences in infection with pathogenic leptospires is consistent with previous studies (De Faria et al., 2007). Increased incidence among male rats might be due to aggressiveness which is sign for maturity.

Isolation of pathogenic leptospires from rats identifies them as a major natural carrier and shedder of leptospires and hence as an important source of infection to humans and other animals. The results showed a much higher proportion (12.7\%) of leptospiral carriage among captured rats from selected NSTC in Peninsular Malaysia. This finding strongly suggests that they serve as reservoir in those areas. Rodent infestation in such places could be due to many factors. One of them is the habitat suitability (Traweger et al., 2006). Shelter, food and water are needed for the survival of rats. Poor management of the training camps and lack of rodent control would lead to the infestation of rats. Moreover, each training camp is equipped with pond which was meant for outdoor activities like swimming and canoeing and it also may serve as water source for rats as well.

Increased population of rats creates problems to the authorities as they caused damage to the properties in the camps and poses a health risk to the trainees when they come into contact with soil or water contaminated with rat's urine. Leptospirosis cases have been reported among Israeli troops following military exercise near the Jordan river (Hadad et al., 2006). All the patients were reported to being exposed in water for $>20 \mathrm{~h}$. Recently, isolation of leptospires has been made from the training camps in Kelantan and Terengganu (Ridzlan et al., 2010). This highlights the quality of the pond habitat for the survival of leptospires outside their host which been discussed by Svircev et al. (2009).

As opposed to NSTC, low carriage rates were detected in oil palm estates $(2.4 \%)$, suburban areas $(1.6 \%)$, PULAPOL Ayer Hitam (4.5\%) and forest habitats (6.7\%). There are many factors that contributed to the lower percentage of carriage rates in these areas. The extensive use of rodenticide and biological control in oil palm estate has successfully reduced the number of rodents in oil palm estates (Hafidzi and Saayon, 2001). However, this finding strongly suggests that $R$. tiomanicus was still a dominant pest in oil palm estates after the research of Wahid (1995). The role of these rats as carrier for leptospires might be considered as not importance, however, this would not eliminate the potential of these rats as reservoir for leptospirosis and its contribution to occupational disease among estate workers as reported previously (Tan, 1964). The dry weather experienced by most areas in Peninsula (Begum et al., 2011) during the trapping period would also be a factor that might contribute to the lowest carriage in rats. Such condition would affect the survivability of leptospires outside host as they require moisture environment (Turner, 1969). Thus, limit the transmission of leptospirosis to other animals.

The present data showed $R$. exulans as carrier for leptospires in forest habitat. Low percentage of leptospiral isolates $(6.5 \%, 2 / 31)$ from trapped rats would not eliminate the potential role $R$. exulans as reservoir for this habitat. These potential rats can be horizontally transmitting infectious leptospires to other rodent species living close to their environments (Jittapalapong et al., 2009). In addition, the rising popularity of Royal Belum Rainforest as a popular destination for adventure travel among the local and foreign tourist may expose them to pathogenic agents including leptospires. This could result in an invasion of non-immune population by pathogenic leptospires which often leads to a more severe manifestation of diseases (Narita et al., 2005). 


\section{CONCLUSION}

This present study provided useful information about carrier rats in Malaysian environment. However, future studies regarding carrier status in other animals in Malaysia needs to be done. Eradication or control of this disease in wild hosts such as rats is not possible and since, these animals serve as potential source of infection for humans, leptospirosis is likely to remain a public health problem. Detection of carrier animals plays a key role to the understanding of epizootic leptospirosis in animal species. Furthermore, characterization of leptospiral isolates is crucial in order to identify the reservoirs and epidemiology associated with human infections.

\section{ACKNOWLEDGEMENTS}

The researchers would like to thank the staff from the Institute for Medical Research (IMR), Kuala Lumpur for technical support. This research was supported by the Ministry of Education Fundamental Research Grant Scheme (FRGS) No: 5523334 and the Ministry of Health, National Medical Research Register NMRR-08-1 093-2248 Grant.

\section{REFERENCES}

Ahmad, S.N., S. Shah and F.M.H. Ahmad, 2005. Laboratory diagnosis of leptospirosis. J. Postgraduate Med., 51: 195-200.

Appassakij, H., K. Silpapojakul, R. Wansit and J. Woodtayakom, 1995. Evaluation of the Immunofluorescent Antibody Test for the diagnosis of human leptospirosis. Am. J. Trop. Med. Hyg., 52: $340-343$.

Athanazio, D.A., E.F. Silva, C.S. Santos, G.M. Rocha and M.A. Vannier-Santos et al., 2008. Rattus norvegicus as a model for persistent renal colonization by pathogenic Leptospira interrogans. Acta Trop., 105: 176-180.

Barcellos, C. and P.C. Sabroza, 2001. The place behind the case: Leptospirosis risks and associated environmental conditions in a flood-related outbreak in Rio de Janeiro. Cad Saude Publica, 17: 59-67.

Barnett, J.K., D. Barnett, C.A. Bolin, T.A. Summers and E.A. Wagar et al., 1999. Expression and distribution of leptospiral outer membrane components during renal infection of hamsters. Infect. Immun., 67: 853-861.
Battersby, J. and J.D. Greenwood, 2004. Monitoring terrestrial mammals in the UK: Past, present and future, using lessons from the bird world. Mammal Rev., 34: 3-29.

Battersby, S.A., R. Parsons and J.P. Webster, 2002. Urban rat infestations and the risk to public health. $\mathrm{J}$. Environm. Health Res., 1: 4-12.

Begum, R.A., C. Siwar, R.D.Z.R.Z. Abidin and J.J. Pereira, 2011. Vulnerability of climate change and hardcore poverty in Malaysia. J. Environ. Sci. Technol., 4: $112-117$.

Bharti, A.R., J.E. Nally, J.N. Ricaldi, M.A. Matthias and M.M. Diaz et al., 2003. Leptospirosis: A zoonotic disease of global importance. Lancet Infect. Dis., 3: 757-771.

Brenner, D.J., A.F. Kaufmann, K.R. Sulzer, A.G. Steigerwalt, F.C. Rogers and R.S. Weyant, 1999. Further determination of DNA relatedness between serogroups and serovars in the family Leptospiraceae with a proposal for Leptospira alexanderi sp. nov. and four new Leptospira genomospecies. Int. J. Syst. Bacteriol., 49: 839-858.

Carter, M.E. and D.O. Cordes, 1980. Leptospirosis and other infections of Rattus rattus and Rattus norvegicus. New Zealand Vet. J., 28: 45-50.

Davis, S., E. Calvet and H. Leirs, 2005. Fluctuating rodent populations and risk to humans from rodent-borne zoonoses. Vector-Borne Zoonotic Dis., 5: 305-314.

De Faria, M.T., D.A. Athanazio, E.A.G. Ramos, E.F. Silva, M.G. Reis and A.I. Ko, 2007. Morphological alterations in the kidney of rats with natural and experimental Leptospira infection. J. Comp. Pathol., 137: 231-238

Ellis, W.A., 1986. The Diagnosis of Leptospirosis in Farm Animals. In: The Present State of leptospirosis Diagnosis and Control. Ellis, W.A. and T.W.A, Little (Eds.). Martinus Nijhoff, Boston and Lancaster, pp: 13-24.

Faine, S., B. Adler, C. Bolin and P. Perolat, 1999. Leptospira and Leptospirosis. 2nd Edn., MediScience, Melbourne, Australia..

Faria, M.T., M.S. Calderwood, D.A. Athanazio, A.J.A. McBride and R.A. Hartskeerl et al., 2008. Carriage of Leptospira interrogans among domestic rats from an urban setting highly endemic for leptospirosis in Brazil. Acta Trop., 108: 1-5.

Gangadhar, N.L., K. Prabhudas, S. Bhushan, M. Sulthana, S.B. Barbuddhe and H. Rehaman, 2008. Leptospira infection in animals and humans: A potential public health risk in India. Rev. Sci. Tech., 27: 885-892. 
Gordon-Smith, C.E., L.H. Turner, J.L. Harrison and J.C. Broom, 1961. Animal Leptospirosis in Malaya: Incidence in rats by sex, weight and age. Bull. World Health Organ., 24: 807-816.

Gravekamp, C., H.V. de Kemp, M. Franzen, D. Carrington and G.L. Schoone et al., 1993. Detection of seven species of pathogenic leptospires by PCR using two sets of primers. J. Gen. Microbiol., 139: 1691-1700.

Hadad, E., A. Pirogovsky, C. Bartal, J. Gilad and A. Barnea et al., 2006. An outbreak of leptospirosis among Israeli troops near the Jordan River. Am. J. Trop. Med. Hyg., 74: 127-131.

Hafidzi, M.N. and M.K. Saayon, 2001. Status of rat infestation and recent control strategies in oil palm plantations in Peninsular Malaysia. J. Trop. Agric. Sci., 24: 109-114.

Harrison, J.L. and S.K. Quah, 1962. The house and field rats of Malaysia. Inst. Med. Res. Bull., 12: 1-38.

Harrison, J.L., 1957. Habitat of some Malayan rats. Proc. Zool. Soc. London, 128: 1-22.

Hinds, L.A., C.M. Hardy, M.A. Lawson and G.R. Singleton, 2003. Developments in Fertility Control for Pest Animal Management. In: Rats, Mice and People: Rodent Biology and Management, Singleton, G.R., L.A. Hinds, C.J. Krebs and D.M. Spratt (Eds.). ACIAR Monograph, Australia.

Jittapalapong, S., V. Herbreteau, J.P. Hugot, P. Arreesrisom, A. Karnchanabanthoeng, W. Rerkamnuaychoke and S. Morand, 2009. Relationship of parasites and pathogens diversity to rodents in Thailand. Kasetsart J., 43: 106-117.

Kee, S.H., I.S. Kim, M.S. Choi and W.H. Chang, 1994. Detection of leptospiral DNA by PCR. J. Clin. Microbiol., 32: 1035-1039.

Khairani-Bejo, S., 2001. Epidemiology of Leptospira interrogans serovars hardjo infection in cattle. Ph.D. Thesis, Universiti Putra Malaysia.

Leon, A., S. Pronost, J. Tapprest, N. Foucher and B. Blanchard et al., 2006. Identification of pathogenic Leptospira strains in tissues of a premature foal by use of polymerase chain reaction analysis. J. Vet. Diagn. Invest., 18: 218-221.

Matthias, M.A., J.N. Ricaldi, M. Cespedes, M.M. Diaz and R.L. Galloway et al., 2008. Human leptospirosis caused by a new, antigenically unique Leptospira associated with a Rattus species reservoir in the Peruvian Amazon. PLoS Negl. Trop. Dis., 2: 1-12.

Merien, F., P. Amouriaux, P. Perolat, G. Baranton and S. Girons, 1992. Polymerase chain reaction for detection of Leptospira spp. In clinical samples. J. Clin. Microbiol., 30: 2219-2224.
Mills, J.N. and J.E. Childs, 1998. Ecologic studies of rodent reservoirs: Their relevance for human health. Emerg. Infect. Dis., 4: 529-537.

Mohamad, M.K., 1992. Mamalia Semenanjung Malaysia. 1st Edn., Malindo Printers, Kuala Lumpur, pp: 182.

Mohamed-Hassan, S.N., A.R. Bahaman and S. KhairaniBejo, 2010. Serological prevalence of leptospiral infection in wild rats at the National Service Training Centres in Kelantan and Terengganu. Trop. Biomed., 27: $30-32$.

Nakagawa, M., H. Miguchi, K. Sato, S. Sakai and T. Nakashizuka, 2007. Population dynamics of arboreal and terrestrial small mammals in a tropical rainforest, Sarawak, Malaysia. Raffles Bull. Zool., 55: 389-395.

Nally, J.E., E. Chow, M.C. Fishbein, D.R. Blanco and M.A. Lovett, 2005. Changes in lipopolysaccharide $O$ antigen distinguish acute versus chronic Leptospira interrogans infections. Infect. Immun., 73: 3251-3260.

Narita, M., S. Fujitani, D.A. Haake and D.L. Paterson, 2005. Leptospirosis after recreational exposure to water in the Yaeyama islands, Japan. Am. J. Trop. Med. Hyg., 73: 652-656.

Noguchi, H., 1917. Spirochaeta Icterohaemorrhagiae in American wild rats and its relation to the Japanese and European strains. J. Exp. Med., 25: 755-763.

Paramasvaran, S., R.A. Sani, L. Hassan, M. Krishnasamy and J. Jeffery et al., 2009. Ectoparasite fauna of rodents and shrews from four habitats in Kuala Lumpur and the states of Selangor and Negeri Sembilan, Malaysia and its public health significance. Trop. Biomed., 26: 303-311.

Perolat, P., R.J. Chappel, B. Adler, G. Baranton and D.M. Bulach et al., 1998. Leptospira fainei sp. nov., isolated from pigs in Australia. Int. J. Syst. Bacteriol., 48: 851-858.

Puan, C.L., A.W. Goldizen, M. Zakaria and G.S. Baxter, 2011. Understanding of relationships between ground cover and rat abundances: An integrative approach for management of the oil palm agroecosystem. Crop. Protect., 30: 1263-1268.

Ramadass, P., D. Latha, A. Senthilkumar, P. Srinivasan and N. Saranya, 2002. Arbitrarily primed PCR-A rapid and simple method for typing of Leptospiral serovars. Indian J. Med. Microbiol., 20: 25-28.

Reitstetter, R.E., 2006. Development of species-specific PCR primer sets for the detection of Leptospira. FEMS Microbiol. Lett., 264: 31-39.

Ridzlan, F.R., A.R. Bahaman, S. Khairani-Bejo and A.R. Mutalib, 2010. Detection of pathogenic Leptospira from selected environment in Kelantan and Terengganu, Malaysia. Trop. Biomed., 27: $632-638$. 
Sharma, K.K. and U. Kalawat, 2008. Early diagnosis of leptospirosis by conventional methods: one-year prospective study. Indian J. Pathol. Microbiol., 51: 209-211.

Shukla, J., 2003. 16S rRNA PCR for differentiation of pathogenic and non-pathogenic Leptospira isolates. Indian J. Med. Microbiol., 21: 25-30.

Silva, F.G., J.C. Freitas, E.K. Anzai, V.Y. Hashimoto and N. Giraldi et al., 2005. Leptospires detection in kidney, liver and uterus of cows slaughtered in Parana State, Brazil. Braz. J. Microbiol., 36: 38-42.

Svircev, Z., S.B. Markovic, J. Vukadinov, S. Stefan-Mikic and M. Ruzic et al., 2009. Leptospirosis distribution related to freshwater habitats in the Vojvodina region (Republic of Serbia). Sci. Chin. C Life Sci., 52: 965-971.

Tan, D.S., 1964. The importance of leptospirosis in Malaya. Med. J. Malaysia, 18: 164-171.

Traweger, D., R. Travnitzky, C. Moser, C. Walzer and G. Bernatzky, 2006. Habitat preferences and distribution of the brown rat (Rattus norvegicus Berk.) in the city of Salzburg (Austria): implications for an urban rat management. J. Pest Sci., 79: 113-125.

Turner, L.H., 1969. Leptospirosis. Br. Med. J., 25: 231-235.

Vedhagiri, K. and K. Natarajaseenivasan, 2010. Characterization of Leptospira borgpetersenii isolates from field rats (Rattus norvegicus) by $16 \mathrm{~S}$ rRNA and LipL32 gene sequencing. Braz. J. Microbiol., 41: 150-157.
Vinetz, J.M., G.E. Glass, C.E. Flexner, P. Mueller and D.C. Kaslow, 1996. Sporadic urban leptospirosis. Ann. Intern. Med., 125: 794-798.

Wahid, M.B., 1995. The Effects of Elaeidobius kamerunicus Faust on Rat Control Programmes of Oil Palm Estates in Malaysia. Institut Penyelidikan Minyak Kelapa Sawit Malaysia, Malaysia, Pages: 50.

Weyant, R.S., P. Edmonds and B. Swaminathan, 1990. Effect of ionic and nonionic detergents on the Taq polymerase. BioTechniques, 9: 308-309.

Wilson, D.E. and D.M. Reeder, 2005. Mammal Species of the World. 3rd Edn., Johns Hopkins University Press, USA.

Wood, B., 2001. Rat control in oil palms and rice fields. Pestic. Outlook, 12: 71-74.

Wood, B.J., 1982. Progress in the control of tropical field rats. Proceedings of the International Conference on Plant Protection in the Tropics. March 1-4, 1982, Kuala Lumpur, Malaysia, pp: 423-428.

Wuthiekanun, V., W. Chierakul, D. Limmathurotsakul, L.D. Smythe and M.L. Symonds et al., 2007. Optimization of culture of Leptospira from humans with leptospirosis. J. Clin. Microbiol., 45: 1363-1365.

Zahedi, M., J. Jeffery, M. Krishnasamy and V.K. Bharat, 1984. Ectoparasites fauna of Rattus rattus diardii from an urban and semi urban environment. $\mathrm{J}$. Malaysian Soc. Health, 4: 25-27. 